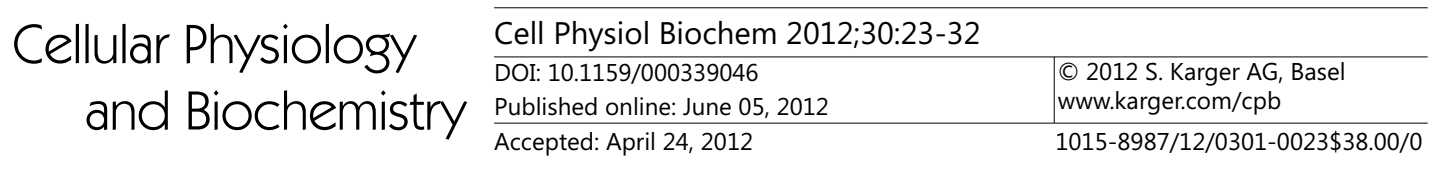

\title{
Dendritic Cells of Synovium in Experimental Model of Osteoarthritis of Rabbits
}

\author{
Xiaoqiang $\mathrm{E}^{1^{\star}}$ Yang $\mathrm{Cao}^{1^{\star}}$ Hongxue Meng ${ }^{2^{\star}}$ Yuebin $\mathrm{Qi}^{1} \quad$ Guangye $\mathrm{Du}^{3} \quad$ Jun $\mathrm{Xu}^{4}$ \\ Zhenggang $\mathrm{Bi}^{1}$
}

\begin{abstract}
${ }^{1}$ Department of Orthopedics, The First Affiliated Hospital of Harbin Medical University, Harbin; 2Department of Pathology, Harbin Medical University, Harbin; ${ }^{3}$ Department of Pathology, NO.3 People's Hospital Affiliated to Shanghai Jiao Tong University School of Medicine, Shanghai; ${ }^{4}$ Department of Orthopedics, The Second Affiliated Hospital of Harbin Medical University, Harbin; ${ }^{*}$ These authors contributed equally to this work
\end{abstract}

\section{Key Words}

Dendritic cells • Osteoarthritis • Synovium • Cartilage

\begin{abstract}
Aims: Dendritic cells (DCs) are critical initiators of immune responses, however, its distribution and role in osteoarthritis (OA) remains largely unknown. This study is to investigate the distribution of DCs in the rabbits' synovium of experimental OA. Methods: Model of OA was established by excising the medial meniscus of both hind knees in New Zealand white rabbits. The grades of synovium and articular cartilage were assessed and scored by hematoxylin eosin stain after 2, 4, 8, and 12 weeks of operation. The distribution of DCs was investigated by immunohistochemistry staining in the synovium from OA rabbits. The levels of IL-1 $\beta$ and TNF- $\alpha$ in synovial fluid were measured by ELISA kits. Results: Molecular markers for DCs, such as DC-LAMP, CD80, CD83, and CD86 were detected in lymphoid aggregations and perivenular infiltration areas in the synovium from OA rabbits. Large numbers of DCs were observed in the synovium in the early stages (2 or 4 weeks) after operation. The number of DCs was significantly increased with the progression of inflammatory grade in synovium in the same early stages. Expression of IL-1 $\beta$ and TNF- $\alpha$ were also increased in the early stages, then decreased with the inflammatory regression in synovium. Conclusion: The data from this study strongly suggested that DCs may play a key role, at least in part, in inflammation of the OA pathogenesis, especially in the early stages of OA.
\end{abstract}




\begin{tabular}{ll|l}
$\begin{array}{c}\text { Cellular Physiology } \\
\text { and Biochemistry }\end{array}$ & $\begin{array}{l}\text { Cell Physiol Biochem 2012;30:23-32 } \\
\text { DOI: 10.1159/000339046 }\end{array}$ & $\begin{array}{l}\text { Published online: June 05, 2012 } \\
\text { www.karger.com/cpb }\end{array}$ \\
\cline { 2 - 2 } & E/Cao/Meng/Qi/Du/Xu/Bi: Dendritic Cells of Synovium in Model of OA
\end{tabular}

\section{Introduction}

Osteoarthritis (OA) is the most common joint disease that characterized by the irreversible erosion and destruction of articular cartilage [1]. The histopathology of OA involves the whole joint and is identified as progressive articular cartilage loss, concomitant sclerotic changes in the subchondral bone, and the formation of osteophytes at the joint margins. Soft tissue structures in and around the joint, such as synovium, ligaments, capsule, and muscles, are also involved [2]. Although OA is generally accepted as one of the commonest degenerative joint disorders, low or medial grade inflammation is detected in osteoarthritis $[3,4]$.

To date, a number of studies have shown the role of immunologic implication in the pathogenesis of OA. First, the immune cells, such as T lymphocytes, B lymphocytes, and macrophages are often found infiltrating into the synovial tissue of patients with OA [57]. Second, immunoglobulins and immune complexes are occasionally detected in the cartilage of patient with OA [8-10]. Third, a subset of autoimmunity against cartilage-related components, such as YKL-39 (a member of chitinase protein family), cyclic citrullinated peptide, cartilage intermediate layer protein, and osteopontin were also detected in patients with OA [11-16]. Fourth, dysregulation of complement in synovial joints has a key role in the pathogenesis of osteoarthritis [17]. Finally, oligoclonal T-cell expansion occurs in synovial membranes in OA $[6,18]$, suggesting activation and proliferation of a limited number of Tcell clones with distinct antigen specificity. Taken all data together, it is clearly demonstrated that the involvement of immunologic pathways take part in the pathogenesis of OA $[6,19$, 20].

Although autoimmune were involved in the pathogenesis of $\mathrm{OA}$, the role of antigenpresenting cells (APC) in the pathological process of OA was not clear. Dendritic cells (DCs) are recognized as the pre-eminent APC due to their ability to stimulate naive $\mathrm{T}$ cells and direct effect on cell function. Studies have shown that DCs participated in and maintained the process of immunopathology in rheumatoid arthritis (RA) [21,22]. DCs are classified as myeloid DCs and plasmacytoid DCs, or immature DCs, and mature DCs [23]. Previous study demonstrated that mature myeloid DCs play a central role in the RA inflammatory process [24]. DCs were also located in the synovium of OA patients [24, 25], but their functions in the pathological process of $\mathrm{OA}$ were still unclear.

We excised the medial meniscus of the rabbits to establish animal model of $\mathrm{OA}$ and these experiments were designed to evaluate the quantity and the distribution of mature DCs in the synovium and investigate their potential roles in the pathology of OA.

\section{Materials and Methods}

Animals and procedures

Twenty-five New Zealand White rabbits (3 months old and irrespective of sex), weighing 2.2- $2.6 \mathrm{~kg}$, were obtained from Experimental Animal Research Center of The First Affiliated Hospital of Harbin Medical University and were randomly divided into five groups of equal numbers.

OA models were established by complete medial meniscectomy. Rabbits were anesthetized by using pentobarbital intravenously ( $30 \mathrm{mg} / \mathrm{kg}$ ). After being shaved and disinfected, both hind knees of the rabbits were underwent total medial meniscectomy via a medial parapatellar arthrotomy to simulate knee instability. After operation, all animals were housed in regular individual cages and permitted free cage activity. After surgery, the rabbits were sacrificed at 2 weeks, 4 weeks, 8 weeks, and 12 weeks. 5 rabbits in control group were sacrificed without operation ( 0 week). The study was in compliance with Harbin Medical University Ethical Council regulations, and the protocol was approved by the Experimental Animals Care and Use Committee of Harbin Medical University.

Histological evaluation was performed by sagittal sections of cartilage from the lesion areas of medial femoral condyle. After dissection, specimens were fixed in $10 \%$ buffered formalin, and then decalcified with 


\begin{tabular}{ll|l}
$\begin{array}{c}\text { Cellular Physiology } \\
\text { and Biochemistry }\end{array}$ & $\begin{array}{l}\text { Cell Physiol Biochem 2012;30:23-32 } \\
\text { DOI: 10.1159/000339046 }\end{array}$ & $\begin{array}{l}\text { Published online: June 05, 2012 } \\
\text { www.karger.com/cpb }\end{array}$ \\
\cline { 2 - 2 } & E/Cao/Meng/Qi/Du/Xu/Bi: Dendritic Cells of Synovium in Model of OA
\end{tabular}

$20 \%$ EDTA solution, eventually embedded in paraffin. Serial sections $(5-\mu \mathrm{m}$ thick) were cut and stained with hematoxylin and eosin (HE). Two independent observers examined the slides by light microscopy (Olympus BX41, Tokyo, Japan) using a modification of the Mankin grading [26]. Histological classification was graded as follows: grade 0: normal; grade 1: surface irregularities; grade 2: pannus and surface irregularities; grade 3: superficial cleft formation; grade 4: deep but localized clefts down to bone; grade 5: large surface defects down to bone; and grade 6: complete disorganizations. The scoring system was based on the average histological changes in five slides of a rabbit.

\section{Histology of Synovial Membrane}

Synovial specimens from the suprapatellar pouch were dissected for histological analysis. The synovial membrane was spread in a cassette then fixed in $10 \%$ buffered formalin and subsequently embedded in paraffin. Serial sections (5- $\mu$ m thick) were cut and stained with hematoxylin and eosin (HE). The slides were inspected by two independent observers using light microscopy (Olympus BX41, Tokyo, Japan). The sections were graded with the synovitis score according to Krenn, et al. [27, 28]: grade 1: no synovitis, sum 0 or 1; grade 2: low-grade synovitis, sum 2-4; grade 3: high-grade synovitis, sum 5-9. Five slides of a rabbit specimen were examined for scoring and the average score was calculated.

\section{Immunohistochemistry}

Paraffin-embedded synovial sections were cut serially (5- $\mu$ m thick) and were deparaffinized and rehydrated. After blocking endogenous peroxidase and antigen retrieval, the slides were incubated overnight at $4^{\circ} \mathrm{C}$ with primary antibodies against DCs cellular markers. These cellular markers for DCs include DC-LAMP, CD80, CD83, and CD86. Dilutions of the first antibodies of DC-LAMP (Rat monoclonal IgG2a; Dendritics; France), CD80 (Rat monoclonal IgG2a; Abcam; UK) CD83 (Rat monoclonal IgG1; Abcam; UK), and CD86 (Rat monoclonal IgG2a; Abcam; UK) were from 1:50 to 1:200. The binding of biotinylated secondary antibodies were visualized by the streptavidin-biotin-peroxidase complex method using 3 , 3'-diaminobenzidine (Sigma-Aldrich, St. Louis, USA) as the substrate. The immunostained sections were counterstained briefly with hematoxylin. Negative controls included the use of IgG isotype controls and omission of the primary antibodies.

Positively stained DCs such as DC-LAMP, CD80, CD83, and CD86 were independently counted by 2 observers in at least 5 fields under a light microscope (Olympus BX41, Tokyo, Japan) in 4 different areas: lining layer area, synovial stroma area, perivenular infiltration area, and lymphoid aggregation area. Then associated images were collected under the digital microscope (Olympus BX41, Tokyo, Japan) with the same chromaticity and pixel. For images analysis, the area of interest (AOI) and the integrated optical density (IOD) were evaluated by Image-pro plus 5.0 software (Media Cybernetics, USA). The average IOD per area in the images were calculated for each 5 different areas.

Measurement of IL-1 $\beta$ and TNF- $\alpha$ in Synovial Fluid

To lave rabbit knee joints, $0.5 \mathrm{ml}$ of saline solution was injected into the joint space through the patellar tendon. After lavation, the needle was reinserted and the fluid was aspirated. The synovial fluid samples were stored at $-80^{\circ} \mathrm{C}$ until assayed. The contents of interleukin-1 $\beta$ (IL-1 $\beta$ ) and tumor necrosis factor- $\alpha$ (TNF- $\alpha$ ) in synovial fluid were measured by ELISA kits (Senxiong Co., Shanghai, China).

\section{Statistical analysis}

Average data were presented as the mean \pm S.D. and analyzed by GraphPad Prism 5.0, and SPSS 11.5 software. Statistical comparisons (performed using analysis of variance, ANOVA) followed by Bonferroni's multiple comparison tests or Dunnett's method) were used as appropriate to evaluate data among groups. A two-tailed $\mathrm{p}<0.05$ was considered to be a statistically significant difference.

\section{Results}

\section{Histological analysis of articular cartilage}

In control group, the surface of normal articular cartilage was smooth and cartilage cells were arranged in order and regular (Fig. 1a). All specimens from the operation groups demonstrated osteoarthritic changes. The surface of the cartilage was an irregularity and superficial cleft formation in two specimens at 2 weeks after surgery (Fig. 1b). At 4 weeks after surgery, vertical clefts were observed and the surface of the aticular cartilage was fibrillated, 


\begin{tabular}{ll|l} 
Cellular Physiology & \multicolumn{3}{c}{$\begin{array}{l}\text { Cell Physiol Biochem 2012;30:23-32 } \\
\text { and Biochemistry }\end{array}$} & $\begin{array}{l}\text { DOI: 10.1159/000339046 } 2012 \text { S. Karger AG, Basel } \\
\text { Published online: June 05, 2012 }\end{array}$ & $\begin{array}{l}\text { Pww.karger.com/cpb } \\
\text { E/Cao/Meng/Qi/Du/Xu/Bi: Dendritic Cells of Synovium in Model of OA }\end{array}$
\end{tabular}

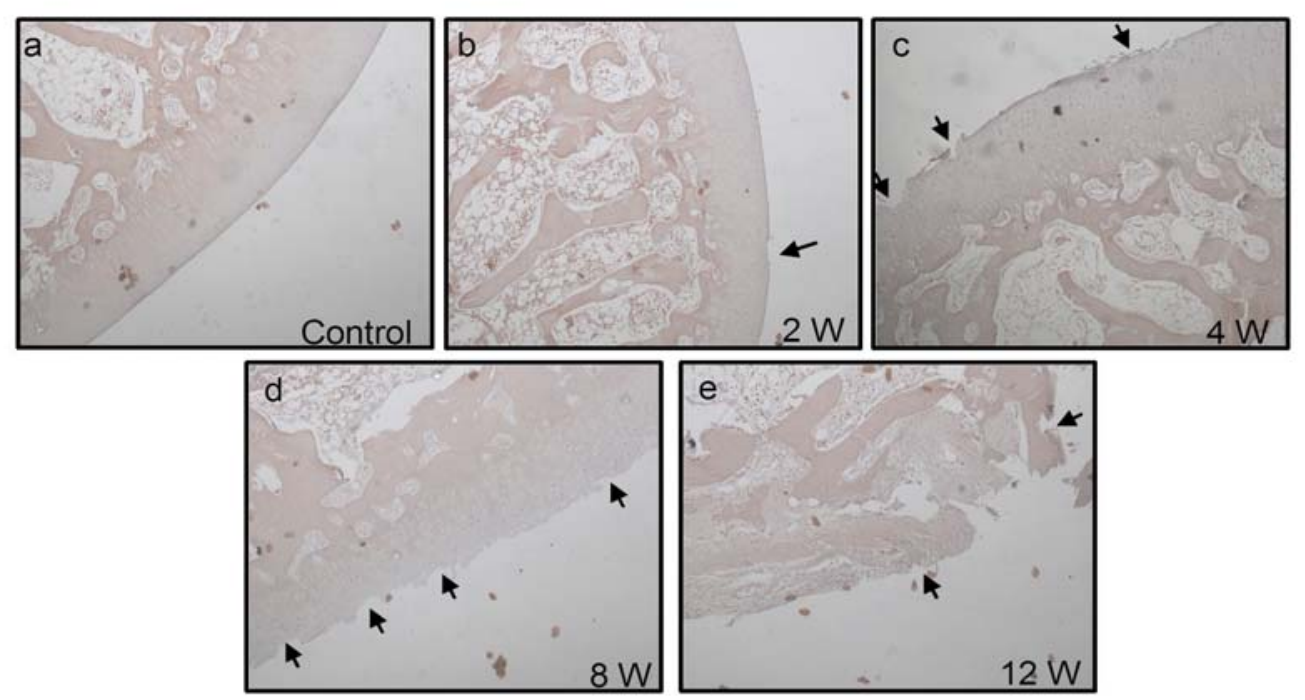

Fig. 1. Histological structure of femoral condyle (HE staining). (a) Control group; (b) 2 weeks after surgery; (c) 4 weeks after surgery; (d) 8 weeks after surgery; and (e) 12 weeks after surgery. In (a) the surface of normal articular cartilage was smooth and cartilage cells were well arranged. The surface of the cartilage was irregularity and disorientation chondron columns cells were seen in (b). Superficial cleft formations were observed in (c). Large surface defects were seen in (d). Ulceration of the cartilage exposing the surface of the subchondral bone was seen in $(\mathrm{e})$. (Magnification $\times 100)$.

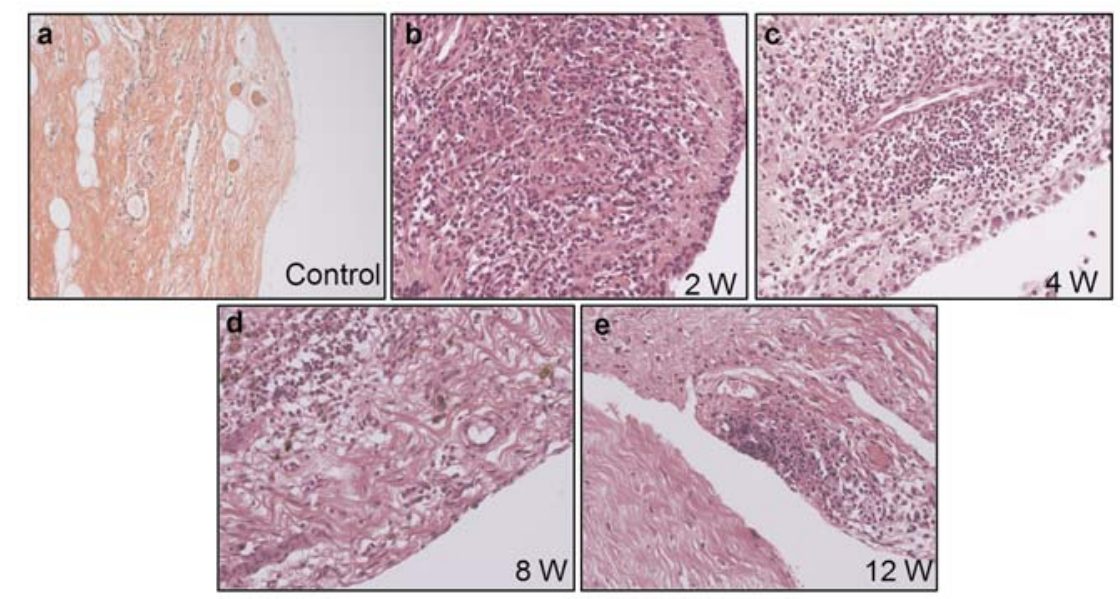

Fig. 2. Histological structure of synovium (HE staining). (a) Control group; (b) 2 weeks after surgery; (c) 4 weeks after surgery; (d) 8 weeks after surgery; and (e)12 weeks after surgery. Hyperplasia of synovial lining cells was marked in (b) and (c). The lining cell layer of the synovium decreased in thickness (d) when compared to the 4-week group specimen. Gross fibrotic proliferation of subsynovial tissue was seen in (e). (a, magnification $\times 200$; b, c, d, e, magnification $\times 400$ ).

but less rough than that of the 8-week group. (Fig.1c). Ulceration was observed in surface of the cartilage and the thickness of the cartilage was decreased obviously at 8 weeks after surgery (Fig. 1d). In 12 weeks after surgery group, complete disorganizations of the articular cartilage were observed and the subchondral bone was exposured in four specimens (Fig. 1e). The histological grade was aggravated from 2 weeks to 12 weeks, average grade was from 1.6 to 5.5 (Fig. 3a). 


\section{Cellular Physiology \\ Cell Physiol Biochem 2012;30:23-32 \\ and Biochemistry \\ \begin{tabular}{l|l}
\hline DOI: 10.1159/000339046 & C 2012 S. Karger AG, Basel
\end{tabular} \\ Published online: June 05, $2012 \quad$ www.karger.com/cpb \\ E/Cao/Meng/Qi/Du/Xu/Bi: Dendritic Cells of Synovium in Model of OA}
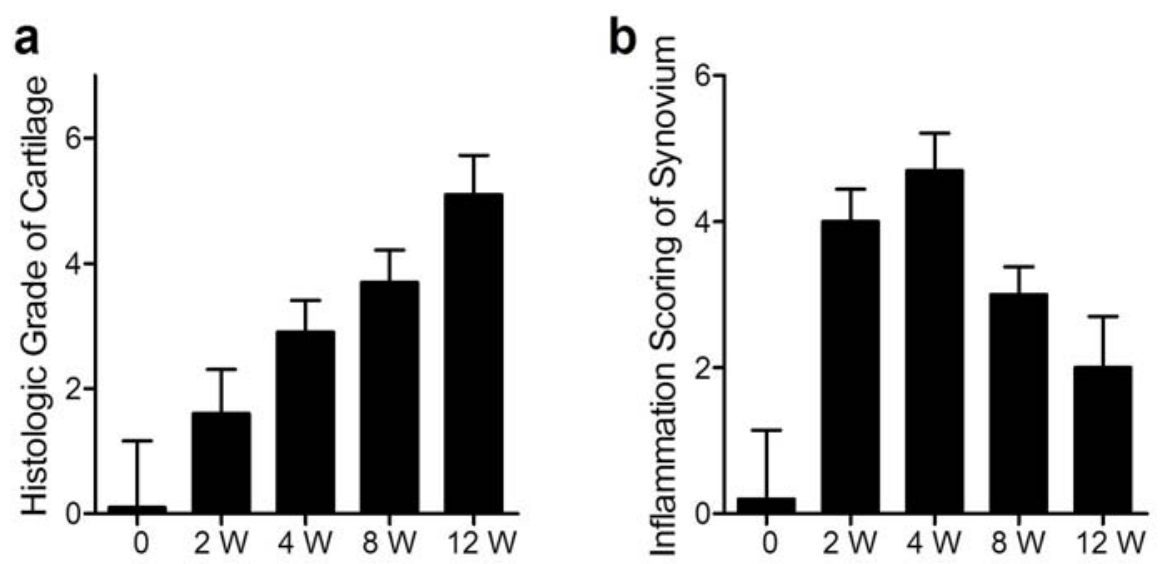

Fig. 3. Histological grading of articular cartilage from medial femoral condyle (a). Inflammation scoring of synovium in rabbits (b).
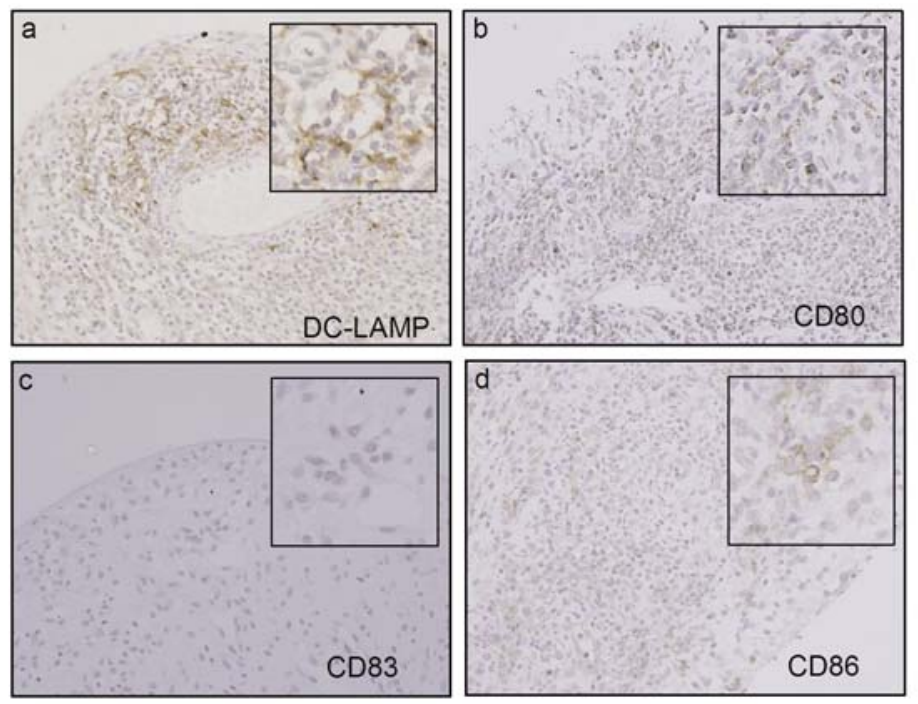

Fig. 4. Immunohistochemistry staining of synovium. (a) DC-LAMP was a marker of mature DCs and expressed in the lymphoid aggregation areas. (b, d) CD80, 86 were costimulate molecules, as markers of mature DCs, expressed in the lining layer and lymphoid aggregation areas. (c) CD83 was a marker of mature DCs and expressed in the lymphoid aggregation areas. Positive staining were brown. (Magnification: $\times 400$, 4-week group).

\section{Histological analysis of Synovium}

Synovitis was observed clearly and the appearance was various in all groups of operated rabbits compared with control group. The synovial lining cell layer became hyperplastic and hypertrophic; the infiltrating mononuclear cells were increased in the synovial stroma and inflammatory infiltrate areas as well (Fig. 2). The synovitis was aggravated at 2 and 4 weeks after surgery compared with control (Fig 2b, 2c). However, the thickness of lining cell layer and density of the inflammatory infiltrate were decreased from 2 and 4 weeks to 8 and 12 weeks (Fig 2b, 2c, 2d, 2e). Eventually, the fibrosis under the lining cell layer was observed in 


\section{Cellular Physiology Cell Physiol Biochem 2012;30:23-32 \\ \begin{tabular}{ll|l} 
and Biochemistry & $\begin{array}{l}\text { DOI: 10.1159/000339046 } \\
\text { Published online: June 05, 2012 }\end{array}$ & $\begin{array}{l}\text { O 2012 S. Karger AG, Basel } \\
\text { www.karger.com/chb }\end{array}$ \\
\cline { 45 - 45 }
\end{tabular}}

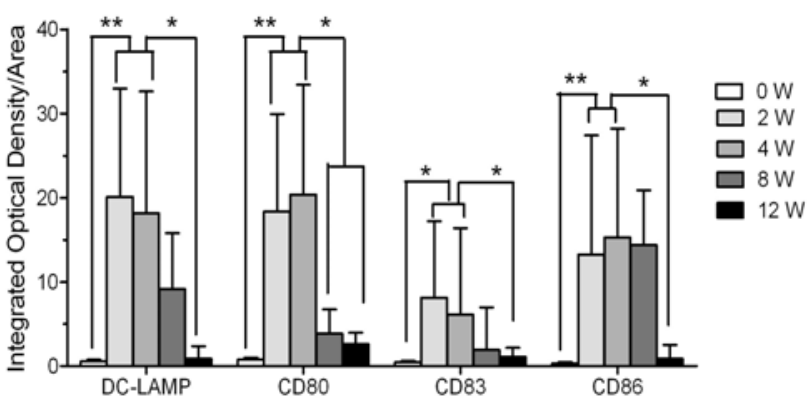

Fig. 5. The number of DCs in the synovium of different group. DC-LAMP, CD80/86 and CD83 were markers for mature DCs. The integrated optical density of DC-LAMP, CD80/86 and CD83 indicated the expression and distribution of DCs in different group. Integrated optical density and area were calculated by Image-Pro Plus software. The significant difference was marked with asterisk. ${ }^{*} \mathrm{p}<0.05,{ }^{* *} \mathrm{p}<0.01$.

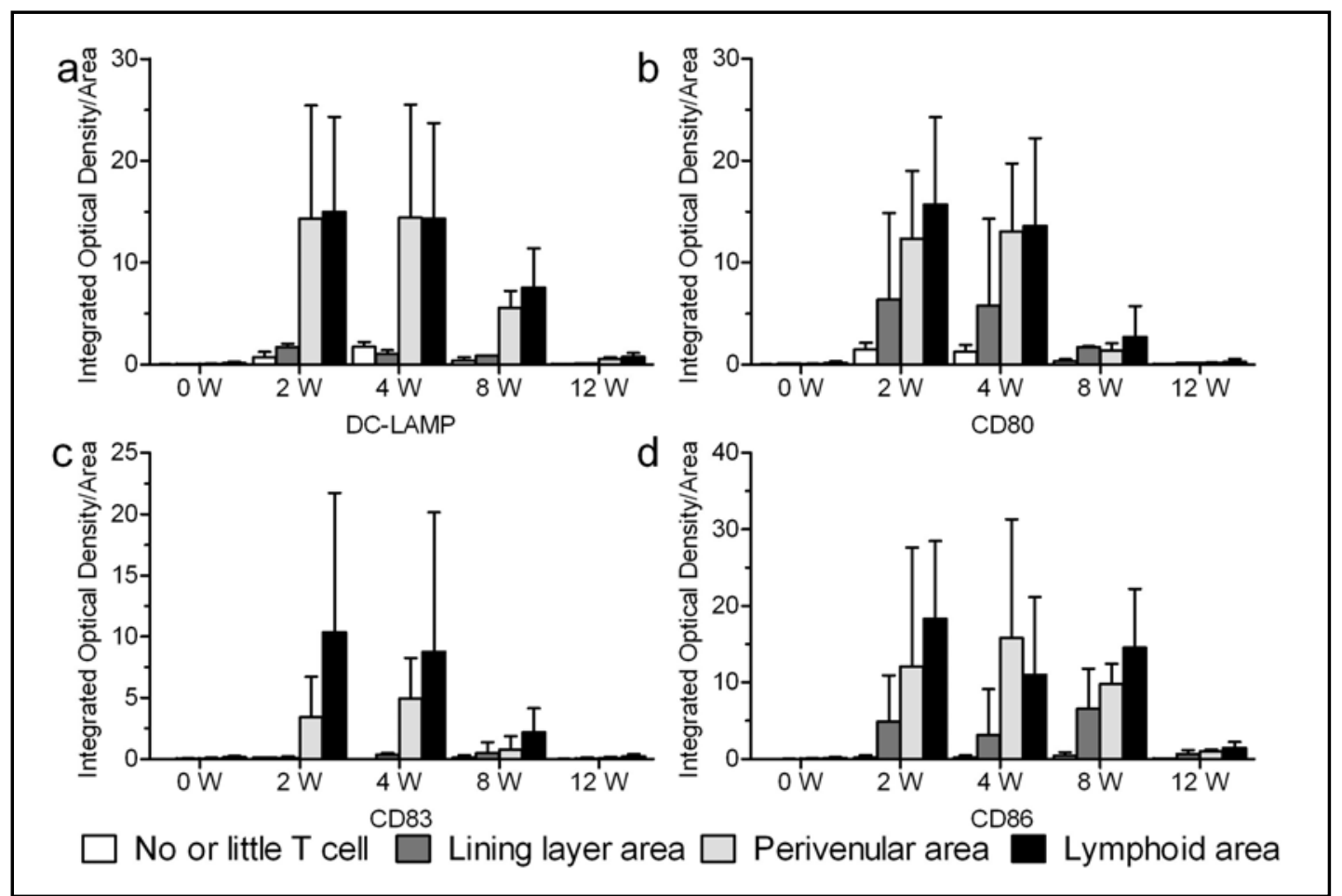

Fig. 6. The quantity and distribution of DCs in different group. Synovium from 25 rabbits were examined by immunohistochemistry and estimations were made in 4 different areas in each section, accordance with different group. (a) DC-LAMP positive cells located mainly in the perivenular infiltration and lymphoid aggregation areas, and increased in 2-week and 4-week groups. (b) CD80 positive DCs increased dramatically in 2-week and 4-week groups, and were detected in the perivenular infiltration and lymphoid aggregation areas, also in the lining layer areas. (c) CD83 positive DCs located in the perivenular infiltration and lymphoid aggregation areas. (d) CD86 positive DCs were found in the similarly location.

the synovium at 12 weeks after operation (Fig 2e).The average inflammation scores for 2, 4 , 8 , and 12 week-group were 4.0, 4.4, 2.5, and 2.0, respectively (Fig. 3b). 


\begin{tabular}{ll|l}
$\begin{array}{c}\text { Cellular Physiology } \\
\text { and Biochemistry }\end{array}$ & $\begin{array}{l}\text { Cell Physiol Biochem 2012;30:23-32 } \\
\text { DOI: 10.1159/000339046 }\end{array}$ & $\begin{array}{l}\text { Published online: June 05, 2012 } \\
\text { www.karger.com/cpb }\end{array}$ \\
\cline { 2 - 2 } & E/Cao/Meng/Qi/Du/Xu/Bi: Dendritic Cells of Synovium in Model of OA
\end{tabular}

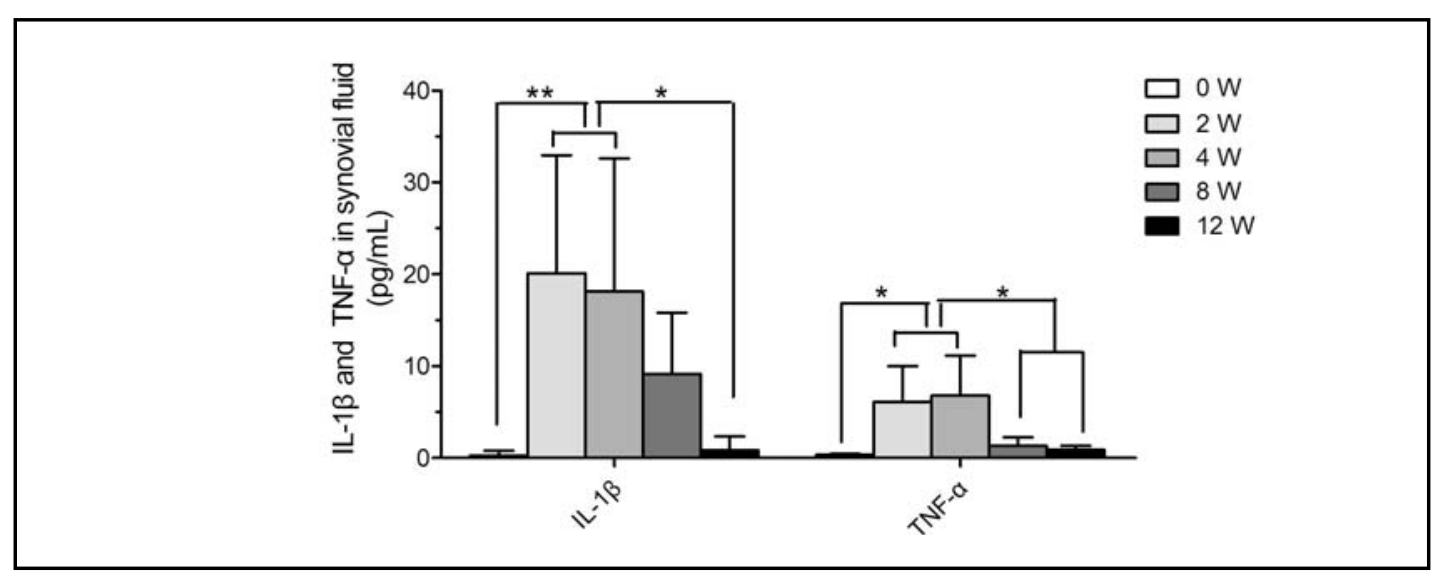

Fig. 7. Contents of IL-1 $\beta$ and TNF- $\alpha$ in synovial fluid. ${ }^{*} \mathrm{P}<0.05$, ${ }^{* *} \mathrm{P}<0.01$.

\section{Distribution and Localization of DCs in synovium}

DC-LAMP, CD80, CD83, and CD86 were cellular markers for mature DCs. DC-LAMP (dendritic cell lysosomal-associated membrane protein, CD208) was originally described as a molecule specifically expressed by mature DCs. CD83 have been known to be the important markers for mature DCs. Mature DCs were expressed high levels of the costimulatory molecule CD80 and CD86. These DC-LAMP, CD80, CD83, and CD86 positively stained cells were displayed at relative higher density in 2-week and 4-week groups (Fig. 4, 5). The number of DC-LAMP positive cells was significantly increased in 2-week and 4-week groups compared with control group, and then decreased in 12-week groups compared with 2-week and 4-week groups (Fig. 5). DC-LAMP positivity DCs were found in the lymphoid aggregation and perivenular infiltration areas (Fig. 4 and Fig. 6). The number of CD80 positive cells was also significantly increased in 2-week and 4-week groups and decreased in 8-week and 12week group (Fig. 5). The number of CD86 positive cells was also increased in 2-week and 4-week group and then decreased in 8-week and 12-week group. CD80 positive DCs were found in the lining layer and perivenular areas, especially in the lymphoid aggregation areas, similar with the distribution of CD86 positive cells (Fig. 4 and Fig. 6). CD83 positive cells were located in perivenular infiltration and lymphoid aggregation areas (Fig. 4 and Fig. 6) and also were decreased in 12-week group, compared with 2-week and 4-week groups (Fig. $5)$.

\section{$I L-1 \beta$ and TNF- $\alpha$ in Synovial Fluid}

IL-1 $\beta$ and TNF- $\alpha$ were prominent and important to inflammation and cartilage destruction in OA. The level of IL-1 $\beta /$ TNF- $\alpha$ can reflect the degree of inflammation. It was shown in Figure 7 that the levels of IL- $1 \beta$ and TNF- $\alpha$ in synovial fluid from each group. The level of IL-1 $1 \beta$ and TNF- $\alpha$ were obviously increased in 2 and 4-week group. With the inflammatory regression, IL-1 $\beta$ was reduced in 12-week group. The level of TNF- $\alpha$ was decreased significantly in 8 and 12-week group, compared with 2 and 4-week group.

\section{Discussion}

We focused on the tissue distribution of DCs in experimental osteoarthritis model of rabbits, and elucidate firstly the relevant information regarding the timing of expression and location of DCs infiltration in experimental OA.

$\mathrm{OA}$ is the most common joint disease, which is associated with a risk of mobility disability in older adults. The dominant clinical symptom has been characterized by a non-infectious chronic inflammatory condition with infiltration of inflammatory cells in the synovium or synovial fluid $[3,29]$. Synovial inflammation could play a role by promoting degradation of 


\section{Cellular Physiology and Biochemistry}

Cell Physiol Biochem 2012;30:23-32

\begin{tabular}{l|l}
\hline DOI: 10.1159/000339046 & $\begin{array}{l}\text { C) 2012 S. Karger AG, Basel } \\
\text { www.karger.com/cpb }\end{array}$ \\
Published online: June 05, 2012 &
\end{tabular}

www.karger.com/cpb

E/Cao/Meng/Qi/Du/Xu/Bi: Dendritic Cells of Synovium in Model of OA

articular cartilage. Proinflammatory cytokines, such as IL-1 $\beta$ and TNF- $\alpha$, are considered to be the principal inflammatory cytokines in OA. IL-1 $\beta$, TNF- $\alpha$, can activate immature DCs and promote it differentiating to mature DCs [30]. DCs also secreted many cytokine, such as IL$1 \beta$, IL-10, TGF- $\beta$ and so on, which activate T lymphocytes and NK cells. IL- $1 \beta$ and TNF- $\alpha$ have a significant effect on chondrocyte, which aggravate cartilage destruction [31, 32].

We found the inflammation grade of synovium was aggravated after operation, but after 8 weeks the inflammation scoring was decreased. Nevertheless the changes in cartilage were aggravated from 2 -week to 12 -week group. The expression of IL-1 $\beta$ and TNF- $\alpha$ in synovial fluid were also increased in 2-week and 4-week group, and then decreased after 8 weeks corresponding inflammation alleviated. The expression of IL-1 $\beta$ and TNF- $\alpha$ may reflect the degree of inflammation in the experimental OA.

In our study, different distribution of DCs was firstly shown during the pathophysiological process of OA in the synovial tissues. Dendritic cells are professional antigen-presenting cells with a key role in both immunity induction and tolerance maintenance. After exposure to pathogenic antigen, DCs undergo maturation and express antigenic peptides on their surface in the context of MHC molecules and express high levels of costimulatory receptor CD80 and CD86 [33, 34]. Maturation DCs present autoantigen to T cells and promote B cell activation in RA synovium, which may be sufficient to drive autoimmune responses in RA [35, 36]. DC-LAMP, CD83, CD80, and CD86 were cellular markers for mature DCs, and these cellular markers positively stained cells can represent the distribution of mature DCs. In our study, these cellular markers positive DCs were mainly observed in the lymphoid aggregation areas of OA synovium. These cellular markers positive cells were significantly increased in 2-week and 4-week group, then decreased in 8-week and 12-week group. So we postulated the number of mature DCs was significantly increased in the early stage of the progression of inflammation (2-week and 4-week group), which may attribute to the aggravated pathological process in OA synovium. The number of mature DCs was decreased in 8-week and 12-week group according with the alleviation of inflammation in synovium. It seemed that DCs play important roles at least in the early stage of OA, but not in the last stage of $\mathrm{OA}$ ( 8 and 12 week).

Taken all data together, our results demonstrated that DCs may be a critical player in the inflammation during the pathogenesis of OA, especially in the early stage. In this study, we mimicked the degradation of cartilage in human OA. Our data showed that the cartilage destruction observed in 12-week group is closely represented the end stage of pathological changes of OA. In this meniscectomy model of OA, the articular cartilage destruction aggravated progressively and dominantly, however, the sever inflammation of synovium could not be confirmed at the same time in this model, suggesting that cartilage damages may, at least, due to the abnormal mechanical pressure exerted on the erosion cartilage surface but not caused by the inflammation. We supposed that the inflammation initiates the destruction of cartilage at early stage. When the cartilage is erosion at the end stage of $\mathrm{OA}$, the abnormal mechanical pressure is the critical reason for the cartilage degradation aggravation.

DCs are receiving increasing scientific and clinical interest due to their involvement in the autoimmunity and immune tolerance. These findings reinforce the knowledge of pathological process of $\mathrm{OA}$ and it lead to the development of new therapeutic strategies for $\mathrm{OA}$ and better understand DCs function in OA.

\section{Acknowledgements}

This work was supported by the National Nature Science Foundation of China (30672127 to $\mathrm{Dr} \mathrm{Bi})$. 


\begin{tabular}{ll|l}
$\begin{array}{c}\text { Cellular Physiology } \\
\text { and Biochemistry }\end{array}$ & $\begin{array}{l}\text { Cell Physiol Biochem 2012;30:23-32 } \\
\text { DOI: 10.1159/000339046 }\end{array}$ & $\begin{array}{l}\text { Published online: June 05, 2012 } \\
\text { www.karger.com/cpb }\end{array}$ \\
\cline { 2 - 2 } & E/Cao/Meng/Qi/Du/Xu/Bi: Dendritic Cells of Synovium in Model of OA
\end{tabular}

\section{References}

1 Creamer P, Hochberg MC: Osteoarthritis. Lancet 1997;350:503-508.

2 Abramson SB, Attur M: Developments in the scientific understanding of osteoarthritis. Arthritis Res Ther 2009;11:227.

3 Pelletier JP, Martel-Pelletier J, Abramson SB: Osteoarthritis, an inflammatory disease: Potential implication for the selection of new therapeutic targets. Arthritis Rheum 2001;44:1237-1247.

4 Hill CL, Hunter DJ, Niu J, Clancy M, Guermazi A, Genant H, Gale D, Grainger A, Conaghan P, Felson DT: Synovitis detected on magnetic resonance imaging and its relation to pain and cartilage loss in knee osteoarthritis. Ann Rheum Dis 2007;66:1599-1603.

5 Sakkas LI, Scanzello C, Johanson N, Burkholder J, Mitra A, Salgame P, Katsetos CD, Platsoucas CD: T cells and t-cell cytokine transcripts in the synovial membrane in patients with osteoarthritis. Clin Diagn Lab Immunol 1998;5:430-437.

6 Nakamura H, Yoshino S, Kato T, Tsuruha J, Nishioka K: T-cell mediated inflammatory pathway in osteoarthritis. Osteoarthritis Cartilage 1999;7:401-402.

7 Revell PA, Mayston V, Lalor P, Mapp P: The synovial membrane in osteoarthritis: A histological study including the characterisation of the cellular infiltrate present in inflammatory osteoarthritis using monoclonal antibodies. Ann Rheum Dis 1988;47:300-307.

8 Jasin HE: Autoantibody specificities of immune complexes sequestered in articular cartilage of patients with rheumatoid arthritis and osteoarthritis. Arthritis Rheum 1985;28:241-248.

9 Pattrick M, Manhire A, Ward AM, Doherty M: Hla-a, b antigens and alpha 1-antitrypsin phenotypes in nodal generalised osteoarthritis and erosive osteoarthritis. Ann Rheum Dis 1989;48:470-475.

10 Xiang Y, Sekine T, Nakamura H, Imajoh-Ohmi S, Fukuda H, Nishioka K, Kato T: Proteomic surveillance of autoimmunity in osteoarthritis: Identification of triosephosphate isomerase as an autoantigen in patients with osteoarthritis. Arthritis Rheum 2004;50:1511-1521.

11 Mollenhauer J, von der Mark K, Burmester G, Gluckert K, Lutjen-Drecoll E, Brune K: Serum antibodies against chondrocyte cell surface proteins in osteoarthritis and rheumatoid arthritis. J Rheumatol 1988;15:1811-1817.

12 Tsuruha J, Masuko-Hongo K, Kato T, Sakata M, Nakamura H, Sekine T, Takigawa M, Nishioka K: Autoimmunity against ykl-39, a human cartilage derived protein, in patients with osteoarthritis. J Rheumatol 2002;29:1459-1466.

13 Tsuruha J, Masuko-Hongo K, Kato T, Sakata M, Nakamura H, Nishioka K: Implication of cartilage intermediate layer protein in cartilage destruction in subsets of patients with osteoarthritis and rheumatoid arthritis. Arthritis Rheum 2001;44:838-845.

14 Sakata M, Tsuruha JI, Masuko-Hongo K, Nakamura H, Matsui T, Sudo A, Nishioka K, Kato T: Autoantibodies to osteopontin in patients with osteoarthritis and rheumatoid arthritis. J Rheumatol 2001;28:1492-1495.

15 Guerassimov A, Zhang Y, Cartman A, Rosenberg LC, Esdaile J, Fitzcharles MA, Poole AR: Immune responses to cartilage link protein and the g1 domain of proteoglycan aggrecan in patients with osteoarthritis. Arthritis Rheum 1999;42:527-533.

16 Du H, Masuko-Hongo K, Nakamura H, Xiang Y, Bao CD, Wang XD, Chen SL, Nishioka K, Kato T: The prevalence of autoantibodies against cartilage intermediate layer protein, ykl-39, osteopontin, and cyclic citrullinated peptide in patients with early-stage knee osteoarthritis: Evidence of a variety of autoimmune processes. Rheumatol Int 2005;26:35-41.

17 Wang Q, Rozelle AL, Lepus CM, Scanzello CR, Song JJ, Larsen DM, Crish JF, Bebek G, Ritter SY, Lindstrom TM, Hwang I, Wong HH, Punzi L, Encarnacion A, Shamloo M, Goodman SB, Wyss-Coray T, Goldring SR, Banda NK, Thurman JM, Gobezie R, Crow MK, Holers VM, Lee DM, Robinson WH: Identification of a central role for complement in osteoarthritis. Nat Med 2011;17:1674-1679.

18 Stamenkovic I, Stegagno M, Wright KA, Krane SM, Amento EP, Colvin RB, Duquesnoy RJ, Kurnick JT: Clonal dominance among t-lymphocyte infiltrates in arthritis. Proc Natl Acad Sci U S A 1988;85:1179-1183.

19 Lorenzo P, Bayliss MT, Heinegard D: A novel cartilage protein (cilp) present in the mid-zone of human articular cartilage increases with age. J Biol Chem 1998;273:23463-23468.

20 Lorenzo P, Neame P, Sommarin Y, Heinegard D: Cloning and deduced amino acid sequence of a novel cartilage protein (cilp) identifies a proform including a nucleotide pyrophosphohydrolase. J Biol Chem 1998;273:23469-23475.

21 Banchereau J, Steinman RM: Dendritic cells and the control of immunity. Nature 1998;392:245-252. 


\section{Cellular Physiology \\ Cell Physiol Biochem 2012;30:23-32 and Biochemistry

22 Lutzky V, Hannawi S, Thomas R: Cells of the synovium in rheumatoid arthritis. Dendritic cells. Arthritis Res Ther 2007;9:219.

23 Shortman K, Naik SH: Steady-state and inflammatory dendritic-cell development. Nat Rev Immunol 2007;7:19-30.

24 Takakubo Y, Takagi M, Maeda K, Tamaki Y, Sasaki A, Asano T, Fukushima S, Kiyoshige Y, Orui H, Ogino T, Yamakawa M: Distribution of myeloid dendritic cells and plasmacytoid dendritic cells in the synovial tissues of rheumatoid arthritis. J Rheumatol 2008;35:1919-1931.

25 Pettit AR, Ahern MJ, Zehntner S, Smith MD, Thomas R: Comparison of differentiated dendritic cell infiltration of autoimmune and osteoarthritis synovial tissue. Arthritis Rheum 2001;44:105-110.

26 Sommerlath KG, Gillquist J: The effect of anterior cruciate ligament resection and immediate or delayed implantation of a meniscus prosthesis on knee joint biomechanics and cartilage. An experimental study in rabbits. Clin Orthop Relat Res 1993:267-275.

27 Krenn V, Morawietz L, Haupl T, Neidel J, Petersen I, Konig A: Grading of chronic synovitis--a histopathological grading system for molecular and diagnostic pathology. Pathol Res Pract 2002;198:317325.

28 Krenn V, Morawietz L, Burmester GR, Kinne RW, Mueller-Ladner U, Muller B, Haupl T: Synovitis score: Discrimination between chronic low-grade and high-grade synovitis. Histopathology 2006;49:358-364.

29 Haynes MK, Hume EL, Smith JB: Phenotypic characterization of inflammatory cells from osteoarthritic synovium and synovial fluids. Clin Immunol 2002;105:315-325.

30 Blanco P, Palucka AK, Pascual V, Banchereau J: Dendritic cells and cytokines in human inflammatory and autoimmune diseases. Cytokine Growth Factor Rev 2008;19:41-52.

31 Fernandes JC, Martel-Pelletier J, Pelletier JP: The role of cytokines in osteoarthritis pathophysiology. Biorheology 2002;39:237-246.

32 Kapoor M, Martel-Pelletier J, Lajeunesse D, Pelletier JP, Fahmi H: Role of proinflammatory cytokines in the pathophysiology of osteoarthritis. Nat Rev Rheumatol 2010;7:33-42.

33 Turley SJ, Inaba K, Garrett WS, Ebersold M, Unternaehrer J, Steinman RM, Mellman I: Transport of peptidemhc class ii complexes in developing dendritic cells. Science 2000;288:522-527.

34 Sarkar S, Fox DA: Dendritic cells in rheumatoid arthritis. Front Biosci 2005;10:656-665.

35 Kowaluk EA: Adenosine modulation: A novel approach to analgesia and inflammation. Expert Opin Investig Drugs 1998;7:535-543.

36 Herholz J, Meloni A, Marongiu M, Chiappe F, Deiana M, Herrero CR, Zampino G, Hamamy H, Zalloum Y, Waaler PE, Crisponi G, Crisponi L, Rutsch F: Differential secretion of the mutated protein is a major component affecting phenotypic severity in crlf1-associated disorders. Eur J Hum Genet;19:525-533. 